\title{
Effectiveness of a Multimodal Intervention for Group Counseling with Children of Divorce in Iran
}

\author{
Mehrdad Hajihasani \\ Department of Counseling, Shahrekord University, Iran
}

Copyright $(2017$ by authors, all rights reserved. Authors agree that this article remains permanently open access under the terms of the Creative Commons Attribution License 4.0 International License

\begin{abstract}
Parental divorce is the issue of most concern for children. The purpose of this article is to describe interventions for children from divorced family. Literature review and references look at divorce groups from multiple perspectives so as to include as many diverse issues as possible. Group counseling helps students understand the wide variety of different issues that arise in the context of groups, helps with universality, and brings support and healing to the very essence of their life. The overall purpose, to empower students to make healthy adjustments in their lives given the immense life changes, is well served by group counseling. Measurable goals and evaluation methods insure a high degree of rigor in the process. Finally, 9 sessions are spelled out in detail including clear objectives, necessary materials and specific strategies so as to insure success in realizing the purpose of the group. Results of multivariate analysis of variance showed that the interventionist model developed by the researcher was effective in improving psychological adjustment $(\mathrm{P}<0 / 01)$. Children of divorce participating sessions succeeded to overcome the negative effects of parental divorce through learning new skills. It is recommended that parents, school counselors and educational authorities benefit the study findings in order to help increase the adjustment in children of divorce.
\end{abstract}

Keywords Children of Divorce, Parental Divorce, Psychological Adjustment, Self-concept, Sense of Belonging, Sense of Meaningfulness, Sense of Competence and Sense of Trust

\section{Introduction}

Change of family structure is associated with creating stress and pressure for all family members. Change of family structure often leads to increased economic and social problems and probability of low psychological adjustment among family members [1]. When family structure changes due to divorce, social isolation may happen to all family members [2]. And also as a result of divorce and consequence of change of family structure, because some methods may initially be opposed, custodial parents are frequently forced to change parenting-related responsibilities [3].

The increased rate of divorce has had important implications for children of divorce [4]. Psychological well-being of children, whose parents are passing transition periods such as divorce, widely has attracted researchers and mental health professionals [5]. There exist different patterns of children reaction to parental divorce [6]. Divorce and living in a single parent family is more often associated with an increase in the stressful events, and this causes adjustment problems in children [7]. Some research such as Amato [4, 2]., Hetherington and Kelly [8], Kelly and Emery [9] have shown that in general, children of divorce have more behavioral and emotional problems compared to normal children. Also, these studies have shown that children of divorce have lower school performance and more communication problems than children from normal families.

The increased number of children of divorce has been associated with many problems in schools. Teachers, administrators, counselors and other supportive professionals have made efforts to respond to their needs in ways that go beyond individual counseling.

Previous research has introduced a number of effective interventionist programs in working with children of divorce (such as Pedro-Carroll, Sutton, \& Wyman [10], Stolberg \& Mahler [11]. The interventions were implemented with parents and children to improve the children well-being. The effectiveness of increased psychological empowerment group model, written by Haji Hasani [12], was investigated in the current study. In the group model, the main topic of the group is acceptance of unique experiences of adolescents from divorced families. Primary objectives of the program is to provide the participants with the following situations: 1) Link in an atmosphere of mutual support with others who have experienced parental divorce, 2) awareness-raising on 
the impact of parental divorce on their family and personal life, and 3) group members' becoming more empowered in terms of such components as: trust, self-concept, sense of belonging, and sense of competence and meaningfulness (12).

Despite the increased rate of divorce of parents in Iran, as a result of which many children are struggling with the consequences of divorce, effective interventions, with the aim of increasing the children adjustment after divorce and making them more empowered, have not been designed to. In addition, review of research conducted abroad in the area of interventionist programs on children of divorce has been mainly indicative of methodological problems. In a few of these studies, replacement has been done randomly and some of them lacked accurate assessment and this restricted the value of the effectiveness of interventions. In addition, since psychological empowerment model was investigated in the study, it seems that this part of the research can be effective in meeting the needs of many children of divorce in Iran also the counselors in the field of divorce can make optimal use of the achievements of this part in their medicinal work.

\section{Methodology}

This study benefited from a post-test control group design within a quasi-experimental method. Statistical population consisted of male children of divorce aged between 12 and 15 years. Available sampling was used. That is, two schools were selected from Shahriyar city's schools according to practical considerations. Then, 16 children of divorce were randomly assigned to the experimental and control groups (8 in each group). The experimental group was exposed to nine one-and-half- an hour group intervention sessions once a week. Structure of the sessions was almost the same. At the start of each session a brief introduction on the topic was given by the group leader and the participants were encouraged to discuss about it. After completing the weekly practice and discussion, the remaining time was devoted to the group members to further share their experiences and discuss about them. A brief description of group therapy sessions is as follows:

Table 1. A brief description of interventionist model

\begin{tabular}{|l|c|}
\hline \multicolumn{1}{|c|}{ Objectives } & Session \\
\hline $\begin{array}{l}\text { - Providing an opportunity for the members to learn more about each other } \\
\text { - Setting rules and objectives for the group }\end{array}$ & First \\
\hline $\begin{array}{l}\text { - Helping the children to manage personal relationships, especially in the family } \\
\text { - Helping the children to clarify, identify and understand the feelings and emotions associated with divorce }\end{array}$ & Second \\
\hline $\begin{array}{l}\text { - Continuing to identify feelings associated with divorce } \\
\text { - Discussing about the problems created by divorce (in the components of psychological empowerment) }\end{array}$ & Third \\
\hline $\begin{array}{l}\text { - Helping children to learn how to confront and deal with the feelings and problems associated with divorce } \\
\text { - Recognizing whether parental divorce has influenced the members' internalized beliefs about themselves. }\end{array}$ & Fourth \\
\hline $\begin{array}{l}\text { - Providing recommendations to the members to make a more positive and stronger self. } \\
\text { - Starting thinking about the choices and decisions about behaviors and actions } \\
\text { - Learning the ways to improve and enrich existing relationships }\end{array}$ & Fifth \\
\hline $\begin{array}{l}\text { - Helping the children to develop logical and true thinking about themselves and divorce } \\
\text { - Continuing to review possible options for behavior and action } \\
\text { - Improving the skills to talk about feelings and needs in the family and society }\end{array}$ & Sixth \\
\hline - Helping the members to assess their attitudes towards divorce and decrease irrational thoughts & Seventh \\
\hline - Making the members aware of the role of spirituality and the need for integrity in personal life & Eighth \\
\hline $\begin{array}{l}\text { - Increasing the positive ways in which the children act, feel and think about their families. } \\
\text {-Summarizing what the group has learned }\end{array}$ & Ninth \\
\hline
\end{tabular}




\section{Instruments:}

Psychological Empowerment Questionnaire:

Psychological empowerment questionnaire was developed and standardized by Haji Hasani [13]. This is a 49-item questionnaire measuring five factors: competence, meaningfulness, self-concept, belonging and trust. The questionnaire items are six-level Likert type: (1) strongly agree, (2) Disagree, (3) Slightly disagree, (4) Slightly agree, (5) agree, (6) Strongly agree. Reliability coefficient of the whole questionnaire, calculated using Cronbach's alpha, was $0 / 83$. To examine construct validity of the questionnaire, Kobasa's [14]. psychological hardiness scale was used and results showed that there is a significant correlation between psychological empowerment scale and Kobasa's [14] psychological hardiness scale ( $r: 0 / 53$, p<0/05). Therefore, construct validity of the questionnaire was confirmed.

Data Analysis Procedures:

To analyze the data at descriptive and inferential levels, mean, standard deviation, and multivariate analysis of variance (MANOVA) were used respectively.

\section{Findings}

There were sixteen participants in the experimental and control groups (eight in each group). The groups were matched for age variable (mean age for both groups was 12/13). Table 2 shows the mean and standard deviation of psychological empowerment components in both the experimental and control groups. According to Table 2, post-test mean of all psychological empowerment components in the experimental group is more than in the control group.

To examine the difference between the two groups concerning the study variables, multivariate analysis of variance test was used. Before running the inferential analysis, assumptions of parametric tests (homogeneity of variance, normality, homogeneity of covariance-variance matrices) were examined:

Table 3 shows that homogeneity of variance is met for self-concept, belonging, meaningfulness, competence and trust components $(p>0 / 05)$. But it is not the case for competence $(p<0 / 05)$. However, given the equal size of the two groups, violation of this assumption is negligible.

Table 2. Mean and standard deviation of psychological adjustment components in the experimental and control groups

\begin{tabular}{|c|c|c|c|c|}
\hline \multirow{2}{*}{ group } & \multicolumn{2}{|c|}{ Experimental group } & \multicolumn{2}{c|}{ Control group } \\
N=8 & Mean & Standard deviation \\
\hline Variable indicator & Mean & Standard deviation & 22.62 & 4.34 \\
\hline Sense of belonging & 33.87 & 4.88 & 29.00 & 3.89 \\
\hline Self-concept & 36.12 & 5.33 & 33.62 & 3.97 \\
\hline Sense of meaningfulness & 40.00 & 3.70 & 27.37 & 5.39 \\
\hline Sense of competence & 34.00 & 2.26 & 26.25 & 5.75 \\
\hline Sense of trust & 35.37 & 5.62 & & \\
\hline
\end{tabular}

Table 3. F Levene's test for examining homogeneity of variance of the two groups

\begin{tabular}{|c|c|c|c|c|}
\hline variable & Df1 & Df2 & F & P \\
\hline Sense of belonging & & 14 & 0.63 & $0 / 43$ \\
\hline Self-concept & & 14 & 0.002 & 0.96 \\
\hline $\begin{array}{c}\text { Sense of } \\
\text { meaningfulness }\end{array}$ & 14 & 0.53 & $0 / 02$ \\
\hline Sense of competence & 14 & 6.73 & 0.86 \\
\hline Sense of trust & & 14 & 0.24 & \\
\hline
\end{tabular}

Table 4. Results of the analysis of Kolmogorov-Smirnov test for normality of dependent variables

\begin{tabular}{|c|c|c|c|}
\hline variable & $\mathrm{Z}$ & $\mathrm{N}$ & $\mathrm{P}$ \\
\hline Sense of belonging & 0.56 & 16 & 0.90 \\
\hline Self-concept & 0.62 & 16 & 0.83 \\
\hline Sense of meaningfulness & 0.43 & 16 & 0.99 \\
\hline Sense of competence & 1.14 & 16 & 0.14 \\
\hline Sense of trust & 0.65 & 16 & 0.79 \\
\hline
\end{tabular}


Results of the analysis of Kolmogorov-Smirnov test (table 4) show that assumption of normality is met for all the study variables $(\mathrm{p}>0 / 05)$.

Results of Box'M test in table 4 show that homogeneity of variance-covariance matrices assumption is met for all the study variables ( $\mathrm{p}>0 / 05)$.

Given that all assumptions were met for all the study variables, multivariate analysis of variance was used to examine between-group differences in psychological components.

Results of table 5 show that there is a significant difference between at least one of the dependent in the study groups (Wilks' Lambda $=8 / 60, \mathrm{p}<0 / 002$ ).

To compare the groups in each of the dependent variables, results of one-way ANOVA test in the context of multivariate analysis of variance are presented in Table 7. The results show that the study hypothesis that 'there is a significant difference between the experimental and control groups in psychological empowerment components posttest' is confirmed. As can be seen from the results in Table 7, obtained significance level for all psychological empowerment components is smaller than significance level of 0/01obtained from Bonferroni correction for multivariate analysis of variance (significance level of 0/05 divided by 5 dependent variables). As a result, given the obtained means, it can be said that mean psychological empowerment components of the experimental group is more than the control group.

\section{Discussion}

Results of multivariate analysis of variance showed that the interventionist model developed by the researcher was effective in improving psychological adjustment (see Table 6).

Importance of "group" can be mentioned as an explanation to justify this study finding. Group counseling is often used as a useful tool in working with children and adolescents. Group therapy serves as a systematic model which help detect healing situations for the members. There exist medicinal factors in the group which help improve the members' psychological state. Yalom and Leszcz [15] identified eleven healing factors in the groups as follows: 1) instillation of hope 2) universality 3) altruism 4) imparting information 5) development of socializing techniques 6) interpersonal learning 7) imitative behaviour 8) catharsis 9) the corrective recapitulation of the primary family group 10) cohesiveness 11) existential factors. Corey and Corey (16) believe that in group conditions, the participants will have the opportunity to express their pure feelings and subjective worldviews. In such conditions, they are openly confronted with others and learn how to cope with the stress from their choice when decoding their daily roles. Therefore, it can be expected that the participants in the groups experience more psychological well-being through experiencing healing factors.

Table 5. Results of Box'M test in table 4 show that homogeneity of variance-covariance matrices

\begin{tabular}{|c|c|c|c|c|}
\hline variable & Df1 & Df2 & Box statistics & P \\
\hline $\begin{array}{c}\text { Sense f } \\
\text { belonging*self-concept * } \\
\text { meaningfulness ، } \\
\text { competence *trust }\end{array}$ & 15 & 789.15 & 36.81 & 0.10 \\
\hline
\end{tabular}

Table 6. Multivariate analysis of variance test for the scores of the two groups

\begin{tabular}{|c|c|c|c|c|c|c|}
\hline Statistical indicator & test & value & F & Hypothesis df & Error df & P \\
\hline \multirow{5}{*}{ Between-group difference } & Pillai's trace & 0.81 & 8.60 & 5.00 & 10.00 & 0.002 \\
\cline { 2 - 8 } & Wilks' Lambda & 0.18 & 8.60 & 5.00 & 10.00 & 0.002 \\
\cline { 2 - 8 } & Hotelling trace & 4.30 & 8.60 & 5.00 & 10.00 & 0.002 \\
\cline { 2 - 8 } & $\begin{array}{c}\text { Roy's Greatest } \\
\text { Root }\end{array}$ & 4.30 & 8.60 & 5.00 & 10.00 & 0.002 \\
\hline
\end{tabular}

Table 7. One-way analysis of variance test in the context of multivariate analysis of variance

\begin{tabular}{|c|c|c|c|c|c|c|c|}
\hline variables & $\begin{array}{c}\text { Source of } \\
\text { change }\end{array}$ & SS & Df & F & P & $\begin{array}{c}\text { Effect } \\
\text { sized }\end{array}$ & Test power \\
\hline Sense of belonging & group & 210.25 & 1 & 9.85 & 0.007 & 0.41 & 0.83 \\
\hline Self-concept & group & 203.06 & 1 & 9.32 & 0.009 & 0.40 & 0.81 \\
\hline $\begin{array}{c}\text { Sense of } \\
\text { meaningfulness }\end{array}$ & group & 162.56 & 1 & 14.41 & 0.002 & 0.50 & 0.94 \\
\hline Sense of competence & group & 175.56 & 1 & 10.24 & 0.006 & 0.42 & 0.84 \\
\hline Sense of trust & group & 380.25 & 1 & 9.05 & 0.009 & 0.39 & 0.79 \\
\hline
\end{tabular}


Various components were used in increased psychological empowerment group model the effectiveness of which has been confirmed in previous research. Among these components, borrowed concepts from Gestalt therapy can be mentioned. Of Gestalt therapy components used in the current study to develop an interventionist model, present tense concept, personal support and autonomy and also emphasis on emotions can be mentioned. Gestalt therapy interventions were used in the interventionist model with the aim of improving the members' autonomy (sense of competence) as well as their emotional discharge. This in turn created a sense of cohesiveness and belonging in the group.

Children of divorce constantly return to the past due to their bitter experience (divorced parents) and suffer from high levels of anxiety, also this group of students, due to their circumstances, is always concerned that others may become aware of their situation, and as a result they suffer from serious fear, anxiety and apprehension. According to Gestalt therapy, anxiety is the gap between the present and future. In Gestalt therapy, it is believed that individuals make themselves anxious by moving away from the present and drowning in the past and future. Gestalt therapists believe that if we can keep such individuals in the present tense, their anxiety level is reduced [13]. So, with these interventions, we expect that the children in the experimental group take an effective step towards autonomy and sense of belonging through expressing their emotions and feelings and taking responsibility. Harman [17] believes that Gestalt therapy emphasizes active and interactive processes between the facilitator and the group. This approach allows the individuals to gain more control in the group. In such groups, the group leader offers support and guidance, but does not directly lead the group.

Among the concepts emphasized in developing the model in the study, spirituality component can be mentioned. Spiritual interventions were used in the current study with the aim of increasing the sense of meaningfulness the group members. Spirituality is a dimension of human being which shows his integrity and relationship with the universe. Relation and integration give the hope and meaning to the human and help him transcend the limits of time, space and material interests, moreover unity in the universe can be seen by spiritual individuals [12]. Spirituality is considered as one of the four components of mental health [18]. Four basic components of individual psychological well-being classified by Moore [18] are as follows: physical, emotional, social and spiritual. Also, spirituality plays a major role in the individual identity [19]. Studies have shown that there is a positive relationship between spirituality, and such values as integrity, hope, meaningfulness, harmony and being at the culmination [20]. Some studies have shown a relationship between well-being and spirituality. Research evidence has shown that spiritual activities lead to better outcomes in mental health and are effective in reducing the signs of stress, anxiety and depression [21]. Prayer and worship is one of the most important strategies in the spiritual individuals. Spirituality and religion gives meaning to the life [22].

The theoretical basics of Green's [23] multimodal approach were used in developing the psychological empowerment model. Of the concepts emphasized in Green's [23] multimodal model and used in this study, emphasis on such concepts such as self-concept, interpersonal relationships and inefficient attitudes can be mentioned.

In the group framework, children who function well in some aspect of their life can serve as a model for the others.

A study by Green [23] showed the effectiveness of multimodal therapy in self-esteem of children of divorce. Given the emphasis on such concepts in psychological empowerment model, the model is expected to have a positive impact on the members' sense of competence and self-concept. Also, the basics of solution-focused theory were used in the model of psychological empowerment. Solution-focused therapy helps individuals create successful solutions to solve their problems. Instead of focusing on the cause and source of the problem, in solution-focused therapy the emphasis is more on the overt behaviors [12].

School counselors and other therapists working with children of divorce are recommended to use the model developed by the researcher to empower children of divorce. We thank all the study participants without whom the research was not possible.

\section{REFERENCES}

[1] Martínez-Pampliega A, Aguado V, Corral S, Cormenzana S, Merino L, Iriarte L. Protecting Children After a Divorce: Efficacy of Egokitzen-An Intervention Program for Parents on Children's Adjustment. Journal of Child and Family Studies. 2015 Dec 1; 24(12): 3782-92.

[2] Amato PR. The consequences of divorce for adults and children: An update. Društvena istraživanja-Časopis za opća društvena pitanja. 2014(1): 5-24.

[3] Fuller-Thomson E, Serbinski S, McCormack L. The rewards of caring for grandchildren: Black Canadian grandmothers who are custodial parents, co-parents, and extensive babysitters. GrandFamilies: The Contemporary Journal of Research, Practice and Policy. 2014; 1(1): 2.

[4] Amato PR. The consequences of divorce for adults and children. Journal of marriage and family. 2000 Nov 1; 62(4): 1269-87.

[5] Hetherington EM, Stanley - Hagan M. The adjustment of children with divorced parents: A risk and resiliency perspective. Journal of child psychology and psychiatry. 1999 Jan 1; 40(1): 129-40.

[6] Hetherington EM. An overview of the Virginia Longitudinal Study of Divorce and Remarriage with a focus on early adolescence. Journal of family psychology. 1993 Jun; 7(1):39.

[7] Amato PR, Keith B. Parental divorce and the well-being of 
children: a meta-analysis. Psychological bulletin. 1991; 110(1), 26.

[8] Hetherington EM, Kelly J. For better or for worse: Divorce reconsidered. WW Norton \& Company; 2003.

[9] Kelly JB, Emery RE. Children's adjustment following divorce: Risk and resilience perspectives. Family Relations. 2003 Oct 1; 52(4): 352-62.

[10] Pedro-Carroll JL, Sutton SE, Wyman PA. A two-year follow-up evaluation of a preventive intervention for young children of divorce. School Psychology Review. 1999 Sep 1; 28(3): 467.

[11] Stolberg AL, Mahler J. Enhancing treatment gains in a school-based intervention for children of divorce through skill training, parental involvement, and transfer procedures. Journal of consulting and clinical psychology. 1994 Feb; 62(1): 147.

[12] Hajihasani M. Developing and investigating the effectiveness of increased psychological empowerment interventionist model in the adolescent males from divorced families. A DISSERTATION Submitted in partial fulfillment of the requirements for the degree of DOCTOR OF PHILOSOPHY In Counselling. Allameh Tabatabei University, Tehran, Iran. 2015.

[13] Hajihasani M. Effectiveness of Geatalt therapy and CognitiveBehavioral Therapy on assertiveness. A DISSERTATION Submitted in partial fulfillment of the requirements for the degree of M.A In Counselling. Allameh Tabatabei University, Tehran, Iran.20 2013.
[14] Kobasa SC, Maddi SR, Kahn S. Hardiness and health: a prospective study. Journal of personality and social psychology. 1982 Jan; 42(1):168.

[15] Yalom ID, Leszcz M. Theory and practice of group psychotherapy. Basic books; 2005 Jul 6.

[16] Corey MS, Corey G, Corey C. Groups: Process and practice. Cengage Learning; 2013.

[17] Harman RL. GESTALT THERAPY WITHOUT TECHNIQUES: A SESSION WITH SUE. Gestalt Journal. 1987.

[18] Mohr WK. Spiritual issues in psychiatric care. Perspectives in psychiatric care. 2006 Aug 1; 42(3):174-83.

[19] Good JJ. Integration of Spirituality and Cognitive-behavioral Therapy for the Treatment of Depression.2010.

[20] O'reilly ML. Spirituality and mental health clients. Journal of psychosocial nursing and mental health services. 2004 Jul 1; 42(7):44-53.

[21] Grabovac A, Clark MN, McKenna M. Pilot study and evaluation of postgraduate course on "the interface between spirituality, religion and psychiatry”. Academic Psychiatry. 2008 Jul 1; 32(4):332-7.

[22] GALLAGHER EB, WADSWORTH AL, STRATTON TD. Religion, spirituality, and mental health. The Journal of nervous and mental disease. 2002 Oct 1; 190(10):697-704.

[23] Green BJ. HELPING children of divorce: A multimodal approach. Elementary School Guidance \& Counseling. 1978 Oct. 